\title{
Agency in translating Une Vie de Boy into English: Exploring translator identity and translation strategies
}

\author{
Felix Awung \\ Department of Media, Language and Communication, Durban University of Technology, South Africa \\ Email: felixa@dut.ac.za
}

\begin{abstract}
Recent research in translation studies has underscored the role of translators as agents. This implies that a translator is not just a neutral conduit of a message from one language to another, but someone who is very much involved in the power interplay that determines the decision making leading to the translation product. It is within this context that this paper seeks to analyse the concept of 'agency' in translation, with specific focus on African literature in European languages. It is worth mentioning that while this type of literature has been the subject of much research, less attention has been given to it in terms of translation. Focusing on a translation by the late John Reed of Ferdinand Oyono's Une Vie de Boy, this paper seeks to show how an understanding of the identity of the translator can lead to an appreciation of his/her translation strategies. It should be noted that translating African culture from one European language to another can be quite a challenging task - especially if the culture is foreign to the translator - due to the fact that cultural value systems are difficult to grasp as they are intricately woven into the texture of the native languages (Bandia 2008). Such a task is even more intriguing since the original text is in itself a form of translation, initially conceived in the African language of the author before being rendered into a European language. In this case, the agency role of the translator would therefore be more significant given that $\mathrm{s} / \mathrm{he}$ is dealing with a peculiar source text that is different from most source texts which are translated between relatively close or non-distant cultures. Through an ethnographic study involving an exploration of the context of the translation production, as well as an interview with Reed, this paper posits that the translator's socio-cultural background tends to influence the nature and extent of his/her intervention in the translation process. This will contribute in shifting the focus of translation assessment from solely the end product to an inclusion of the translator's identity.
\end{abstract}

Keywords: agency, translator identity, ethnography, African literature

\section{Introduction}

Recent research on translation studies is increasingly incorporating sociological models in translation analysis. This approach underscores the fact that the translator can no longer be viewed merely as a neutral conveyor of a message; rather, $s$ /he should be viewed as an agent involved in a situation of power relations which influences the nature of his/her interventions 
during the translation process. This agency role enables the translator to make decisions in the translation process that have far-reaching impacts on the target culture. It is worth mentioning that, while this area is increasingly dominating research in translation studies, much of the research is based on the Eurocentric model, with only a few researchers advocating the incorporation of other geo-cultural models (see Tymoczko 2007, Marais 2011). It is within this context that this paper seeks to explore how a translator's agency operates in African literature. It thus seeks to aid in understanding how the different power actors within a translation context relate to each other, and how this relationship influences the translation product. Given that African literature is more oratory in its originating culture, it would be useful to understand the agentive role of the translator in the representation of such literature. Furthermore, given that African literature in European languages is peculiar in that it is a form of translation in itself (Bandia 2008), it would be interesting to explore how translation agents handle this type of transfer. Focusing on Houseboy, a translation by the late John Reed of Ferdinand Oyono's novel entitled Une Vie de Boy, this paper seeks to show how an understanding of the identity of the translator can lead to an appreciation of his/her translation strategies. This paper adopts an ethnographic method that elucidates the translator's perspective so as to give a better understanding of the translation process. This could lead to further research on the extent to which a translator's socio-cultural background can influence the nature and extent of his/her intervention in the translation process.

\section{Literature review}

As far as agency in translation studies is concerned, it is necessary to first situate this paper within the context of what previous research has exposed. Agency theorists have highlighted the fact that translation analysis should take a sociological approach, given that translation is carried out within a conflicting network of a sociological nature. In this light, Munday (2010, 2012) utilises Bourdieu's sociological model to argue that the translator's background is always an influence on the decisions s/he makes during the translation process, resulting in him/her being (un)consciously biased either towards the source or target text. In the same vein, Kung (2009) argues that translation is carried out within a context of power relations, and that there are macro-level factors which influence the choices and strategies of the process. Using Latour's Actor Network Theory model and Bourdieu's notion of 'capital', she highlights the fact that the translator's identity determines his/her agentive position in this network of power relations. Mialet (2010) asserts that translators are not just neutral mediators, but are social agents who have a key role to play in introducing new ideas and perspectives, and in shaping ideologies. As such, sociological considerations should be incorporated in the analysis of translation.

Other theorists highlight the fact that translators are not neutral conduits of messages, but are power agents who work within a context of political and cultural power relations. In this light, Tymoczko (2010) argues that translation takes place within a context in which dominant and resistant cultural narratives conflict with each other. This places the translator as a third force in a power interplay, whose choices are always (un)consciously partial to one side of the conflict or the other. The problem with this view is that it is based solely on literary translations, and does not seem to consider oral cultures. This is contrary to what recent research in translation studies has emphasised, which is that the frontiers of theorising translation should be extended to consider other cultures. Even though, in her recent works, Tymoczko emphasises the need for these new frontiers of translation theories, much of her analyses are still based on Western 
data. Similarly, Baker $(2006,2010)$ considers translation to be involved in a conflict of narratives that shape, promote or resist political ideology. This implies that, instead of being a simple conveyor of a message, a translator becomes a powerful agent who can choose what (not) to translate, and manipulate a message in order to impact in a particular way upon the recipient's cultural narrative. She holds that, in this way, the translator contributes to the political idealisation of one narrative or the other. Again, the focus here is on written texts and no other text types or communication forms are incorporated, such as the oral forms that prevail in communities of which the languages do not have written versions.

Some theorists also argue that there needs to be a shift from the Eurocentric model of translation analysis to a more holistic one which incorporates other geo-cultural realities. Accordingly, Tymoczko (2007) asserts that the theorisation of translation studies needs to be more flexible to include non-Western realities. She holds that there are limitations to the Eurocentric approach, which concentrates on written communication and literary texts, and advocates a more holistic approach which considers other cultural forms of communication and text types. This position is significant in translation studies because it highlights the fact that there are differences in the Western and non-Western models of communication and such differences should be considered in any translation analysis. For example, the African form of communication is generally oral in nature, and the contexts of translation on the continent also differ from those in the West. In the same vein, Marais (2011) argues for a "localisation" process in translation studies that would incorporate forms of communication and functions of translation. Focusing on the African example, he highlights the fact that communication is more oral in African societies, and translation is employed in various ways in different situations as well as having different functions. He therefore suggests that, instead of trying to apply a universal approach, translation studies should be theorised according to the different realities of the various geo-cultural situations that exist in societies. The strength in Marais' (2011) argument is that it raises a new perspective in translation studies, namely localisation. In other words, instead of having an incorporating theorisation of the discipline, he argues for an approach that theorises differently according to the specific realities of each socio-cultural context.

Other proponents of the agency approach to translation studies hold that, in the domain of translation analysis, translators should be viewed as agents involved in a binary conflict of domination versus resistance. In this regard, Venuti $(1998,2013)$ argues that translation operates within the context of Western cultural domination over minority cultures. He calls for a resistant approach in the field of translation which would valorise more of the marginalised cultures, to the detriment of the canons of the dominant culture. Milton and Bandia (2009) view this conflict of domination and resistance as the context in which translation takes place. The authors (2009:3) argue that translators in such situations become agents of resistance and identity creation by adopting an approach which enables their marginalised cultures to resist

the onslaught of dominant global languages through a deliberate translation of themselves into such global languages, which they subvert through innovative linguistic practice to assert their identity on the world stage. 
This raises the issue of the translator's identity and how it may influence the way s/he translates. In other words, adopting a translation strategy that resists a dominant force or creates a particular identity would very much depend on the cultural identity of the translator in question.

Other researchers of the sociological approach to translation studies consider translators to be agents of cultural mediation who represent the Other in the target culture. In this light, Sturge (2007) argues that translators are important agents of representation since the source text is inaccessible to the target culture except through the translator-agent. The translator's interventions during the translation process then become the means through which $\mathrm{s} / \mathrm{he}$ can shape the way the target culture views the source text. Sturge (2007) thus suggests that, for a translator to carry out this role successfully, s/he needs to have full knowledge of the source text's content, culture and author. The strength in Sturge's argument is that it calls for an ethnographic approach on the part of the translator, so as to be able to fully interpret the source text. Bandia (2008:159) relates this to African literature in European languages and argues that translators of such literature are important agents of representation who deal with a different text type, since

[t]he writing of orality and the practice of literary heteroglossia involved in African Europhone literature makes for a peculiar source text that is uncharacteristically different from most texts translated between relatively close or non-distant languages and cultures.

Bandia (2008:161) then raises the question as to who is better placed to translate such texts:

Is it the Western-educated African writing in what is for some a second language, but who is intimately familiar with the logos of African culture? Or should it be a native European translator for whom the colonial language is a mother tongue, but who may not be able to internalise the deep structures of African sociocultural reality?

This also raises the issue of how the translator's cultural identity plays a major role in determining the nature of the interventions $\mathrm{s} / \mathrm{he}$ carries out during the translation process. The strength in Bandia's argument is that he emphasises the peculiarity of the text type involved in African literature in a European language, and the need for this peculiarity to be considered during the translation process. He also highlights the fact that the identity of the translator of such literature is important since it is most likely going to influence his/her choices and strategies during the translation process.

\section{Une Vie de Boy and Houseboy}

Ferdinand Oyono's Une Vie de Boy was published by Julliard in Paris in 1956. It denounces the ills of French colonialism in Africa in general, and in Oyono's native Cameroon in particular. It should be noted that Oyono remains one of the most prolific anticolonial novelists from Africa and has published two other novels: Le Vieux Nègre et la Médaille ("The Old Man and the Medal") in 1956 and Chemin D'Europe ("Way to Europe") in 1960. A fourth novel, Le Pandemonium, was announced for publication in 1960 (Brown 2004:40), but it is said to have 
been withdrawn from the publisher immediately after Cameroon gained independence from France and Oyono became part of the new administration. This was because the novel's anticolonial tone was harsh, and it was thought that it would adversely affect the relationship between France and the new Cameroonian administration.

Une Vie de Boy presents the situation in which colonial rule was introduced as something beneficial to Africans, while it was actually intended to subjugate, humiliate and exploit them. The novel narrates the story of Joseph Toundi, a young African who works for a white colonial administrator. Toundi initially regards his association with the white administrator as a lucky opportunity for him which puts him above his African peers in terms of social status. However, he subsequently learns the dark side of colonialism through unfortunate events that see him finally run away from Cameroon to die in neighbouring Spanish Guinea. Toundi's rhetorical question "[...] what are we black men who are called French?" highlights the deceptive ideals of French colonialism as something that was meant to bring civilisation and development to Africans, thereby elevating them to the same level as the French. The story is told by Toundi himself in a diary he keeps, a practice he learns from his white master. The novel is written in a simple and satirical style very much embedded in the cultural orality of the author. The preamble in the translation states that the original was written in Ewondo (a language of central Cameroon) which highlights the fact that the author intended the style to carry much of his native oral structure.

It should be mentioned that, at the time of publication of Une Vie de Boy, it was not easy for the works of African writers to be accepted by the publishing houses in France as these works were not considered to be of the same standard as the European classical ones. Another reason was that the publishing houses were not very open to works denouncing European colonisation. However, after the Second World War, French public opinion was more sympathetic towards the marginalised and, as such, major publishing houses began to accept colonial works by African writers, which were usually published as marginal publications. It was within this context that Julliard, one of the major Paris-based publishing houses at the time, became involved in African literature and, in addition to Oyono's, published many other francophone works from Africa.

The English translation of the novel was done by the late John Reed (1929-2012) and was published as Houseboy by Heinemann in 1966 as part of its African Writers Series. Reed was British and spent more than 15 years in southern Africa working as an English teacher. He was also an expert in African literature and taught, edited and translated other published works from the continent. It must be noted that the publishing policies in France during the colonial period were similar to those in the United Kingdom (UK). British publishers were reluctant to publish works by Africans, as their works were judged to be inferior and would not interest the British readership. It was for this reason that the African Writers Series was set up to cater for the works of African authors. The fact that the series was established as a marginal trend is an indication that the literature which was indeed published was not of the same standard as that of the mainstream Heinemann publisher. This in itself portrays the position of the publisher as far as African literary works are concerned, and it would be interesting to see how translators of literary works relate to publishers' ideological positionings. 


\section{Interview findings}

For the purposes of this study, an ethnographic methodology was employed. This method is predominantly used in sociological and anthropological research, but it is increasingly being incorporated in translation studies. An ethnographic methodology enables the researcher to understand the context surrounding human actions from the perspective of those involved in the actions. According to LeCompte and Schensul (2010:2), ethnographic research requires the researcher to

first discover what people actually do and the reasons they give for doing it before trying to interpret their actions through filters from their own personal experience or theories derived from professional or academic disciplines.

What this implies is that, rather than subjectively analysing actions, it is necessary to understand their cultural context and obtain the target population's opinion of these actions in order to understand what goes on. The use of this research design usually requires the researcher to inhabit the world of the target population and conduct interviews with its members, so as to be able to frame their behaviours and beliefs within a socio-political and historical context (LeCompte and Schensul 2010:12).

As previously mentioned, this research design is increasingly being incorporated in the analysis of translation processes (see Sturge 2007, Hubscher-Davidson 2011) because it provides an insider's view of the context of translation. This is important as an understanding of the translator's perspective can go a long way to shed more light on the nature of the translation process. It is within this context that I conducted an interview with John Reed. This was carried out via email because he was based in Ireland and it was not possible for me to meet with him physically. The interview questions focused on issues of initiation, communication with the publishers and author, exposure to source-text context, the purpose of translation, the translation process and the outcome of the translation. Reed's responses were then analysed according to the context of production (section 4.1), the translation process (section 4.2) and the end result (section 4.3).

\subsection{Context of production}

From the interview findings, it emerged that the translation process was actually initiated by Reed himself. This in itself is an example of the translator's agency role in that $\mathrm{s} / \mathrm{he}$ can decide whether or not to translate a particular work, so as to either support or contest a particular ideology. It is in this light that Tymoczko (2007:xxi) asserts that translation is "a deliberate and conscious act of selection, assemblage, structuration, and fabrication". Furthermore, Baker (2006) notes that, rather than being "passive receivers of assignments" (2006:105), many translators and interpreters actually "initiate their own translation projects and actively select texts and volunteer for interpreting tasks that contribute to the elaboration of particular narratives".

However, it should be mentioned that, in the case of Une Vie de Boy, the initiation process was complex in nature given that Reed did not initiate it for translation in its entirety, as he had only translated an excerpt of the novel in an article he published on African literature (see Reed 
1963). This caught the attention of the target-text publisher who then initiated the process to have the whole novel translated. The publisher's decision to order for the translation was, however, subject to a motivational report from Reed. This portrays another level of the agency role a translator can play in a translation project given that, in this case, Reed had to influence the publisher's decision on the importance of a translation of this novel.

According to Fisher (cited in Baker 2010:28), "[a]11 forms of human communication function to influence the hearts and minds of others - their beliefs, values, attitudes, and/or actions". Relating this to the translation of Une Vie de Boy, it can be asserted that Reed became an advocate of a translation that promoted a particular ideology, and contributed in shaping the publisher's mindset into endorsing that ideology. Considering the influence of publishers in shaping societal mindsets in general, it becomes obvious that Reed's contribution had a farreaching impact on the target-text society. Would he ever have thought of translating the entire text for the purpose of translation? Would the target-text publisher have become interested in a translation of the novel had they not been given a glimpse of it through the translated excerpt? These questions highlight the complex nature of the initiation process in question.

It is also worth mentioning that, during the initiation process, Reed had no contact with either the author or the source-text publisher. Given that, for copyright reasons, the publication of a translated work cannot take place without the authorisation of the source-text publisher or author, the exclusion of the translator at this level of the negotiations shows the limit of the translator's influence when it comes to the interaction of other agents within the context of a translation production. However, the translator plays a significant role in the initiation process when one considers the fact that the source-text publisher and author could not have been approached without the prior willingness of the translator to translate the work; the translator is, as such, an important agent in the power relations of a translation's context of production.

Another significant aspect that emerged during the interview was that Reed was remunerated for the translation. This raises important questions when one seeks to understand the translator's position as an "interested representer" (Munday 2012). If the translator is an interested party in the translation process, in relation to the ideologies of the source- and target-text cultures as well as the translator's habitus, what place does economic power occupy in the equation? Does it feature as another power centre or is it a tool in the hands of a power agent who, in this case, is the publisher? Would economic power be able to shift the translator's allegiance from one ideology to another? Translators, like other professionals, have economic needs, and there are bound to be situations in which those needs clash with personal ideologies. Translation studies therefore need to explore the role that economic power plays in positioning a translator as an agent of the translation process by considering how this role may differ from one society to another. The economic situation of the West is different from that of developing countries and, as such, the impact of economic power would not be the same. In Africa, for example, translation is carried out with an aim towards development (Marais 2011), the implication here being that poverty is widespread and economic empowerment is a main priority. How would an African translator resolve the problem of satisfying his/her economic needs and resisting or adhering to a particular ideology? These are issues that have been neglected by translation studies and which need to be addressed in order to better understand the role of the translator as an agent. 
The final issue to consider in the context of the translation of Une Vie de Boy is that of time pressure. It was revealed in the interview that Reed was given four months in which to translate the novel. The argument here does not concern whether or not this time frame was adequate; rather, the argument is that when a deadline for the completion of a translation assignment is set by the publisher, or any other concerned party, it may become a source of pressure if the translator's opinion is not sought in relation to his/her ability to work within the deadline. Such pressure may influence some of the choices made during the transfer process, which may not be the same if the translator is given enough time for a thorough analysis that ensures a more comprehensive interpretation and transfer.

Another aspect that may have put pressure on Reed is the fact that the translation was done manually. It is true that today's technological advancements have significantly lessened this type of pressure, since translators now have computers and facilitating software to make their work easier. However, there are still different challenges pertaining to the context in which translators operate. The provision of briefs, or the absence thereof, is one of the issues which can either facilitate or complicate the translator's job. While a brief would usually serve the purpose of ensuring the translator aligns him-/herself with the position of the client, its absence may lead to the position of the translator dominating the process, which may subsequently create a conflict between translator and client ideologies. A brief can therefore contribute in the harmonisation of positions between the translator and the client during the transfer process.

\subsection{Translation process}

Concerning the translation process, it is worth beginning this section by stating that Reed had an interest in the promotion and dissemination of African literature. His exposure to this literature came as a result of his 17 years of experience as an English teacher in Africa, since African literature in English was part of his syllabus. This fact raises the issue of the translator as an interested "representer of the source words of others" (Munday 2012:2). The implication here is that part of Reed's interest as an agent of the translation process was the desire to disseminate and promote African literature, as his record indicates that he had completed scholarly works of translation, editing and research on this type of literature. It then becomes obvious that his interest would most likely have influenced the choices made in the nature of the transfer from the source text to the target text. Venuti (1998) argues that depending on whether a translator wants to promote the dominant literary poetics of the West or valorise the minority literature, $\mathrm{s} /$ he may either adopt a domesticating or foreignising approach respectively. If this was a factor in Reed's case, it would further substantiate the fact that his choices would have been influenced by his relationship with African literature.

A second important issue regarding the translation process is that, as previously mentioned, Reed had no contact with Oyono, the source-text author. This implies that Reed's interpretation of the source-text context would have been mostly circumstantial and, as such, prone to stereotyping. Bandia (2008:161) asserts that a European translator of African literature "may not be able to internalise the deep structures of African sociocultural reality". It can be argued that the years of exposure to African literature could have given Reed the necessary insight into the embedded realities of this literature type. However, it should be noted that he mostly lived and worked in southern Africa and only rarely travelled to other parts of Africa. This is compounded by the fact that his infrequent travels to other parts of Africa never included Cameroon, where the novel in question is set. Sturge (2007:22) argues that, in order to have a 
comprehensive understanding of the source-text culture, an "emic approach" is necessary as meaning is context-specific. Consequently, Sturge (2007:24) argues that the representation of the source-text culture should be carried out "through an interpretative reconstruction of the original words' linguistic context, cultural context and immediate setting".

Therefore, to say that exposure to one part of Africa is sufficient to fully grasp the socio-cultural realities of other parts of the continent, is holding on to the erroneous assumption that Africa is homogeneous. Such assumptions are themselves borne of Western stereotypes which are shaped by narratives which contribute to the development of an identity.

When asked about the challenges of cultural transfer in the process, Reed said that he did not find it difficult because French and English functioned similarly, if not identically, in their colonial settings. Again, this indicates an assumption of homogeneity in the colonial experiences of Africa. Recall that the French and British colonial systems differed significantly from each other, implying that the language of the coloniser functioned differently too (Abdulaziz 2003). The French policy was that of assimilation which aimed to convert Africans into black French persons. There was thus a vigorous policy of cultural transformation aimed at eroding the African culture and replacing it with that of the French. Africans were therefore educated to dress, eat, talk and think like the French. The French language was to be embraced by the colonised Africans which led to a process of domestication of the language, especially amongst the uneducated. The result was a French version that was limited to a particular sociocultural region. The British colonial system, on the other hand, implemented an indirect rule system without attempting to transform the culture of the colonised. In this case, English was more a language of administration and education and was never intended to replace the African languages (Abdulaziz 2003:185). This difference in functionality implies that the local varieties of French and English that emerged in the respective colonial settings were different in nature.

\subsection{Analysis of the product}

An analysis of the translation of Une Vie de Boy has been carried out utilising findings from the interview with Reed, the context of the translation production and the parallel comparison of the source- and target texts. The first issue to address in this case is the success (or failure) of the translation. It is important to note that I have not assessed the translation in terms of accuracy, since individual assessment is likely to be subjective. Instead, I have attempted to explore contextual factors to determine what conclusions can be drawn from them. The main factor to consider here is the degree of the target culture's acceptance of the translation. According to Reed, "[...] Houseboy has had long print runs both in the UK and in America" (personal communication). Moruwawon (2012:46) also states that the novel and its translation remains one of the favourite literary works written by an African author to have been published, and has "consistently featured in academic institutions across the globe". This clearly indicates that the published translation was a great success. The question now arises as to whether this type of translation acceptance can be used to conclude that the translation process was successful in this case. Given that the target culture had no exposure to the source text due to the language barrier, and had to rely on Reed's representation, could the members of the target culture be in a position to know whether or not the translation is a successful representation? In addition, Reed said in the interview that his purpose was to give the target-text readers "an experience corresponding to that of a francophone reader of Oyono's original" (personal communication). It is important to note that, while the original is considered one of the most 
prolific African colonial novels in French, the translation is equally known to be one of the best African colonial novels in English. This implies that Reed's objective has been met by his translation and, if one were to go by the Skopos school of thought (Vermeer 2000), can be deemed successful. This then raises the issue of translation as manipulation, and the question then arises as to what extent the translator's intervention can shift the source-text content and style in order to shape a particular perspective in the target culture. In this light, Paloposki (2009:189) argues that

[t]he extent to which translators are free to decide on the contents of their work varies, depending on the position of the translator in question, on the literature to be translated, and the expectations of the readers, among other factors.

An assessment of the success (or failure) of a translation is thus very much based on the position of the assessment. Furthermore, the analysis of such an assessment would need to consider the various factors that are likely to influence it.

Going back to a previously mentioned yet important point, it is intriguing that the English version of the novel has been accepted as an original and not as a translation. In other words, it has been read and studied as "African literature in English". This again raises the question as to whether this implies a success on the part of the translation, or ignorance on the part of the readership. One reason that may explain this phenomenon is the fact that African writers in European languages write in a style which is in itself a type of translation (Bandia 2008), since they conceive the stories in their native languages before translating them into the European languages. Bandia (2008:161) argues that, in this way, "the colonial language of writing seems to serve as a mere conduit for an indigenous literature with its own content and modes of expression". This then makes it difficult to distinguish between original and translated African literature in European languages, unless one is exposed to the two languages and cultures in question.

It is also important to mention that Reed adopted a predominantly foreignising approach in the translation. While I do not intend to venture into the sensitive debate of foreignisation versus domestication (Venuti 1998), I consider Reed's translation one which preserves the local colour and oral structure of the source text. Reed explained that he wanted to give the target readership the same experience as the original readership. If one interprets "same experience" to mean "same target audience response", then it can be argued that he intended to domesticate, as this approach would most likely elicit sameness of response (Venuti 1998). However, it would be hasty to assert that this was Reed's intention. Recall that he was an expert in African literature in his professional life, which implies that he was well exposed to the nature of African literature in English. Consequently, his intention might have been to elicit the same response in his English translation that an original African text in English would have elicited. With this in mind, I assert that Reed has generally taken a foreignising approach, which preserves the local colour of Oyono's source text, as is demonstrated in his transfer of culture-bound terms such as idioms, exclamations and local names.

It is important to note that there are cases of mistranslation in Reed's version, which can be attributed to his lack of sufficient exposure to the source-text world. Examples include les essessongos (translated as "essessongo trees"), gâteau maïs (translated as "maize cake") and 
bâton de manioc (translated as "cassava sticks"). These three French phrases are coinages from the local languages that have been embraced by the French dialect spoken in Cameroon.

In the first phrase, essessongos means "elephant grass", but Reed translated it as "essessongo trees". Any reader not exposed to the Cameroonian connotation of this word would be lost, or even misled, as to its meaning. This is because the notion of 'tree' in the translation is very misleading from 'grass' which is the original connotation.

The second phrase, gâteau maïs, is actually a coinage from French to denote a local dish made from mashed maize that is wrapped in banana leaves and then boiled. The notion of 'cake' actually refers to the shape of the food. Rendering it as "maize cake" is thus misleading, especially as there is no paratext for guidance.

The final phrase, bâton de manioc, came about in the same way as gâteau maïs. Bâton de manioc is a local dish of cassava paste wrapped in banana leaves which is then formed into the shape of a baton and boiled. "Cassava sticks" is therefore a mistranslation as it may give the impression that people from this setting eat sticks.

As previously mentioned, these mistranslations are the result of insufficient exposure on the part of the translator given that, as Bandia (2008:187) argues, cultural items present "[s]pecific challenges as their occurrences in the European language are often the result of the author's creative endeavour to capture them as they exist in African languages". Insufficient exposure to such contexts may then lead to interpretations based on generalisations, assumptions and, in certain situations, stereotypes. These stereotypes in themselves are born of narratives that develop a particular identity that influences the perception of the Other.

Another important feature to include in the analysis of Reed's translation is his use of Cameroonian Pidgin to translate français petit nègre (FPN). I contend that Reed's use of Cameroonian Pidgin to translate FPN is an error of judgement because the two languages are different in nature and function differently in their societies. FPN is a form of "broken French" that was spoken by uneducated Africans who worked for the European colonialists, whereas Cameroonian Pidgin is a creole of which the development in West Africa can be traced back to the $15^{\text {th }}$ century with the arrival of Portuguese slave merchants on the West African coast (see Awung 2013). FPN developed from the combination of African languages and European languages such as Portuguese, French, English and German. Its current English-based form took shape with the extended presence of the British along the coast of West Africa. It is thus a language on its own with distinct grammatical and prosodic structures (Neba, Chibaka and Atindogbé 2006). Cameroonian Pidgin can therefore not function as the equivalent of FPN because the latter is a sort of slang, while the former is an autonomous language with mothertongue speakers and is even spoken in some non-Anglophone West African countries (see Awung 2013). This argument is clearly evidenced by the fact that Cameroonian Pidgin was equally spoken in the French-speaking Cameroonian community during the colonial period. Furthermore, this explains why Oyono also uses it in the source-text, as can be seen with the term washman which Reed maintains in the English translation.

It is thus evident that a more thorough investigation of the source-text context would have prevented the instances of mistranslation discussed in this paper. I therefore argue that Reed's 
interpretation of Oyono's text has been influenced by the general perception of Western narrative that views Africa not only as a homogeneous entity, but also as inferior to Europe.

\section{Conclusion}

In this paper, I have highlighted the fact that the translator is not a neutral mediator of a cultural message, but an interested actor whose product is the result of his/her interaction with other power agents involved in the translation process. Focusing on John Reed's translation of Ferdinand Oyono's Une Vie de Boy, I have investigated the various agents involved in the translation process and how their roles may have influenced Reed's choices. The analysis of the context of production has revealed that, generally speaking, the translator has to position him-/herself in relation to the power interests of the source-text author and culture, the sourcetext publisher, the target-text publisher and the target-text culture. Further, I have argued that, in such a complex situation, the translator's identity is highly instrumental in determining how $\mathrm{s} /$ he positions him-/herself in relation to the other power agents involved. It has also been highlighted in this paper that a translator's identity is the product of a particular cultural and societal narrative that leads to a particular ideology, and subsequently influences the decisions $\mathrm{s} /$ he makes during the translation process. This has been demonstrated by an exploration of the workings of John Reed, whose European ideology has played a significant role in determining his perception of the source-text culture, despite the fact that his exposure has to some extent limited the impact of said ideology in the interpretation and transfer of the source text's message.

Based on the findings of the paper, I support the view that an analysis of the translation process should extend beyond the product and incorporate the translator's perspective and context. This is because translators operate within different cultural contexts which have different communication dynamics. An inclusive approach to translation studies would thus produce a more holistic picture as well as newer insights into the theorisation of the discipline.

\section{References}

Abdulaziz, M. 2003. The history of language policy in Africa with reference to language choice in education. In A. Ouane (ed.) Towards a multilingual culture of education. Hamburg: UNESCO Institute for Education. pp. 181-199.

Awung, F. 2013. The pidgin alternative in the English medium educational system of Cameroon. Asian Journal of Research in Social Sciences \& Humanities 3(4): 9-17.

Baker, M. 2006. Translation and conflict: A narrative account. Manchester: St. Jerome.

Baker, M. 2010. Translation and activism: Emerging patterns of narrative community. In M. Tymoczko (ed.) Translation, resistance, activism. Amherst and Boston: University of Massachusetts Press. pp. 23-41.

Bandia, P.F. 2008. Translation as reparation: Writing and translation in postcolonial Africa: Manchester: St. Jerome. 
Brown, S. 2004. African literature past, present and future. In F. Rosati (ed.) The quest for democracy: Writings on Nigerian literature in English. pp. 35-46.

Hubscher-Davidson, S. 2011. A discussion of ethnographic research methods and their relevance for the translation process. Across Languages and Cultures - A Multidisciplinary Journal for Translation and Interpreting Studies 12(1): 1-18.

Kung, S. 2009. Translation agents and networks, with reference to the translation of contemporary Taiwanese novels. In A. Pym and A. Perekrestenko (eds.) Translation research projects 2 . pp. 123-138.

LeCompte, M.D. and J.J. Schensul. 2010. Designing and conducting ethnographic research: An introduction. Plymouth: Altamira Press.

Marais, K. 2011. The representation of agents of translation in (South) Africa: Encountering Gentzler and Madonella. Translation and Interpreting Studies 6(2): 189-206.

Mialet, E.B. 2010. The sociology of translation: Outline of an emerging field. MonTI 2: 153172.

Milton, J. and P. Bandia (eds.) 2009. Agents of translation. Amsterdam: John Benjamins.

Moruwawon, B.S. 2012. The trauma of colonialism in Ferdinand Oyono's "Une Vie de Boy". Michigan Sociological Review 26: 42-57.

Munday, J. (ed.) 2010. Translation as intervention. London: Continuum.

Munday, J. 2012. Evaluation in translation: Critical points of translator decision-making. New York: Routledge.

Neba, A.N., F.E. Chibaka and G.G. Atindogbé. 2006. Cameroon Pidgin English (CPE) as a tool for empowerment and national development. African Study Monographs 27(2): 39-61.

Oyono, F. 1956. Une vie de Boy. Paris: Julliard.

Oyono, F. 1966. Houseboy. London: Heinemann.

Paloposki, O. 2009. Limits of freedom: Agency, choice and constraints in the work of the translator. In J. Milton and P. Bandia (eds.) Agents of translation. Amsterdam: John Benjamins. pp. 189-208.

Reed, J. 1963. Between two worlds: Some notes on the presentation by African novelists of the individual in modern society. Makerere Journal 7: 1-14.

Sturge, K. 2007. Representing others. Translation, ethnography and the museum (Translation Theories Explored 11). Manchester: St. Jerome.

Tymoczko, M. 2007. Enlarging translation, empowering translators. Manchester: St. Jerome. 
Tymoczko, M. (ed.) 2010. Translation, resistance, activism. Massachusetts: University of Massachusetts Press.

Venuti, L. 1998. The scandals of translation: Towards an ethic of difference. London: Routledge.

Venuti, L. 2013. Translation changes everything: Theory and practice. New York: Routledge.

Vermeer, H.J. 2000. Skopos and commission in translational action. In L. Venuti (ed.) The translation studies reader. London and New York: Routledge. pp. 213-221. 